\title{
Associate Music Performance as a Method of Blind Students Creative Rehabilitation
}

\author{
Valery Korablyov \\ Russian State Specialized Arts Academy \\ Moscow, Russia
}

\begin{abstract}
United music playing as a method of creative rehabilitation for blind disabled students, and the specifics of orchestra classes for blind students are discussed in this article. The author's long experience, which includes the organizing of an orchestra of folk instruments of RSSAA, its constant leader and conductor, shows efficiency of this method for disabled students.
\end{abstract}

Keywords-music; united music playing; principles of teaching; conductor; leader; repertoire policy; educational process

\section{EXISITING RESEARCH}

According to statistics, there were $45 \mathrm{mil}$ blind people in the world in 2005, and $135 \mathrm{mil}$ people with limited sight ability. Every year 2 million blind people are added, and by 2020 that number will have doubled. Only $19 \%$ of the people have no pathology sight. That is why social adaptation and rehabilitation of this part of society attracts a great circle of scientists of different profiles and different specialists.

Research has shown that a person with no sight is lacking $85 \%$ of all the world information; his movement system disrupts, his feelings become less acute, his psychics demoralizes and he keeps degrading. All the social rehabilitation systems of blind people are aimed at the neutralization and liquidation of blindness and poor sight negative results. It includes the increase of blind people's social wealth based on a complex of social-economic, legal, pedagogical, cultural, moral, psychological and medical measures aimed at their social integration.

There are not so many researches and methodologies of work with the blind people. There are actually no scientific works on the issues of orchestra and associate performance of the blind. Of the existing works, we should mark the reports and articles of: V.Z. Kantor, N.S. Mikhalnichenko, N.N. Kolokoltseva, E.V. Selezneva, J.V. Pavlova, S.V. Dudenina, and V.N. Kulakov. But all these researchers touch upon issues connected to the rather narrow areas of activity, such as: library work, administration, staff development, specifics of teaching, the role of computational factors of the choir students, stage and accordion students, pedagogical problems of individual work with the disabled students, their everyday life organization, etc.

Specialists working with the orchestras and blind ensembles have their own practical observations and methods, which, as a rule, are not brought outside the professional group. Many leaders are the members of the World Blind Association, which makes contacts, writing and reading of particular literature difficult. Others are just enthusiasts of their work and do not try to solve any scientific problems - trying only to solve educational problems. But almost everybody realizes that they create something new in their activity in theory and practice of the popular music performance. Sometimes in private conversations an idea is expressed of the systemization of the accumulated experience, scientific development of the issues connected with the ensemble-orchestra combinations and the necessity of the creation of the best methodologies of teaching of such students` categories.

\section{DIALECT UNITY}

For the blind and poor-sighted people, who do not have clear sight images, sound perception and arts based around it are important. Nothing but music expressing ideas, emotions and different information has equal emotional and informative impact. Blind people are very sensitive to music, mainly to the popular music, which is close to their spirit, is always «on the ear», and easy to learn and understand.

Associate music playing is one of the most effective communication means for blind people, as it touches such life sides as communication, education, and artistic development. Any orchestra is the best expression of the collective solidarity of the performers. On one hand it is a union of the people, where every person is a personality; on the other hand it is a living body with its general ideas, moods, plans and scenic image. This dialectic unity is a stimulus of perfection of every performer in particular and the orchestra in general.

\section{THE HISTORY OF ASSOCIATE ART}

The roots of the associate art of the blind people are rather deep. Since the ancient times such names as Boyan, Homer, Avasi, Ostap Veresay came to us. The art of blind musicians is a bright phenomenon all over the world. An acute ear, perfect music instrument mastering, and unusual thinking specify it. Such people were treated as prophets, their art was deeply expressed in the popular genres, they were supposed to have a gift of healing and provision. There were whole ensembles of such talented people. There are examples of small blind music theaters and traveling bands. 
Beginning in the XIth century the Slavs created the socalled «vatagas» (groups) of the traveling blind getters and actors. There was the village «Scaramouch», who lived with the princes and served the state. There are very few documents proving these phenomena, but there are some chronicles, legends, frescoes and old songs texts.

Only in the XIXth century the first specialized educational institutions are created. In 1917 Levshinskaya opened a specialized school for the blind, which was reorganized in 1923 into a music college. Gregory Liubimov, a founder of the unique professional State orchestra for the 4string domra was teaching there and was the State master class of the folk instruments. 1921 World Blind Association is created. In 1933 a specialized school for the blind was created and in 1954 a music boarding school college was created on its basis.

After WWII former military men, rear front workers, and children who were wounded would with great enthusiasm join music orchestras and find a great stimulus and a rehabilitation opportunity. In 1944 a composer and music teacher I.M. Papkov initiated a music boarding school in the town of Zagorsk for the newly blind. The school existed until 1951 and music college subjects were studied in it. All over the Soviet Union there are numerous blind societies, clubs, organizations, ensembles, choirs, theaters and orchestras. They prepare high-level specialists.

In the 1950's in a Moscow blind society club a birth blind but very energetic leader and highly educated musician Semen Tsepelev began creating a folk instruments orchestra. The first performance took place in 1957. The uniqueness and the beauty of the sounding of a new folk orchestra brought many people nearer. At the same time there appear some other groups: an academic choir and a drama theater. The level of performance quickly grows and soon they enter the most prestigious stages of Moscow, including the Kremlin, and tour different Russian regions. The most gifted people with eyesight defects get professional music education in colleges, institutes, and conservatories and continue their work.

In the 1960's professional stage unions and concert groups are created, where blind actors work together with the seeing ones. And finally in 1991 a State Specialized Arts Institute is open, which trains actors, painters, solo musicians as well as ensemble performers and choir and orchestra masters. In 2013 the institute changed its name into an Academy. The institute trains a lot of student groups, from duets to a choir or an orchestra, who seriously study different programs and get awards at different competitions and festivals, including the international ones. Blind music art gains absolutely new quality level.

\section{ASSOCIATE ART ACQUiSITION}

The academic process and the work with musicians with disabilities has a number of specific traits. For example, there are different historically formed ways of learning the notes for the blind musicians. In additions to the RSSAA curriculum orchestra class there are special recommendations for every student category. For the totally blind students it is learning by ear, by fingers, dictations, the soloist following, ensemble, improvisation, and the Brail system. Disabled students with eyesight remaining use big size notes and a magnifying glass.

The development of the new computer music programs makes the studying process easier also for the conductor. «Finale» program allows to type, edit and reproduce different notes. «Sonar» program allows to sound the notes using the high quality tones, close to the natural ones to find false notes in the parts before general rehearsal for the blind and the poorly-sighted to enlarge the party in a monitor. «Jaws» program allows to change tones, rhythm ensemble structures, show the monitor information and is compatible with most of the programs. The combination of these three computer algorithms one may get an instrument, increasing the artistic potential of performers and the conductor.

Repertoire policy and conducting methods also have their specifics. Since many blind orchestra performers have to learn their parts by heart, the repertoire should also be structured. First of all it is the priorities of repetitions songs, rondos, 3-5 parts, etc. They try to avoid big parts or development compositions, drum parties or well-rhymed compositions. Looking for some fresh material the conductors turn to the popular classics, solo instruments pieces and soloists accompaniment.

Rehearsal process in the orchestra is where most disabled students can function like the masses: they are individual, group and orchestra classes. But most part of the classes are given to individual group classes. A combined usage of all the above-mentioned methods is recommended, but personal and musical qualities of a student should also be taken into consideration. The most talented musicians should be given a chance to consider their parties independently with the following correction by a conductor according to the notes. Finally, it will be useful to develop several instrument playing skills. Unusual orchestra siting is possible considering the specifics of the performers.

The concert performance creates a number of orchestra conditions, which allows blind students to join, accelerate or slow down silently. For example, counting the tacts, a light triangle touch or the tambourine sticks immediately before the introduction or a difficult part. Pauses rhythm, fernmatas, harmony or melody specifics can also be marked in such a way. In particularly difficult cases it is possible to miss several parts of tact, in some parts especially composed harmony organizing background.

An important part of the teaching process is the beginning and the end of an orchestra rehearsal. Organization of a class where the blind students are also present has the administrative and artistic aspects but also the moral and psychological ones. Correct time measurement and clear rehearsal tasks allow the orchestra players energy to accumulate. It disciplines the students and allows better results. The end of an orchestra rehearsal is a kind of summing up of an activity of multiple structures of an orchestra, which leads to the following activity and rehearsals as demonstration of results of students activity. The process should not be authoritarian, but very diplomatic 
and tactful in order not to touch participants ' personal pride. Besides regular comparison of every student's contribution to the process is necessary. Seeing participants may decode it by the conductor's facial expression, gestures or behavior blind musicians should listen to the recommendations. Individual conversations are recommended as well as the system of marks and credits.

At the same time an orchestral-ensemble class has a number of specific issues. The final result of any rehearsal is a concert - an academic concert, a festival or a contest. It is created by a whole group of participants, not by a single participant. That is why such teaching forms as free visiting, independent repertoire studying, tutorials, distant studying or a different orchestra internship should be used very cautiously. It results in poor sound feeling, sound extraction, general professional level and creates difficulties for the conductor in reaching good results and leads to the performance mistakes.

Domineering principles of the work of a conductor differ in music bands of different kinds. Professional orchestras have many different ways to influence its participants, but the material stimulus is the priority. Amateur orchestra is based on a deep motivation of every participant that his work is needed, their personal interest and voluntary class visiting. The student orchestra has none of those, so the teacher's decision of «passed/not passed» credit does not really reflect the entire picture. There should be very strict requirements that should be followed by every student: $100 \%$ presence, well studied material, grounding of class missing (including medical leaves), individual plan, coordinated with a teacher or a dean and disciplinary offense punishments (exam failure, telling off, expelling). It is important to train with the students respect for social norms and responsibilities not only at college, but also at a performance.

Students are demanded not only the knowledge of their parties and their perfect performance, but also their thorough examination, group interests presentation, attention and good preparation for the rehearsals and concerts, independent difficulties studies, careful attitude to the orchestra instruments, if necessary performance of another party. It is necessary to remember that the general one reflects individual art. The scope of artistic life is so wide - from a colleague aid to a disabled person help to producer's activity, creating artistic plans for the conductors and improvement of already existing ones, to the organization of the orchestra touring.

\section{THE LEADERS}

The leaders of the orchestra are the responsible people from the orchestra. The orchestra leaders organize active rehearsal work and orchestra work, take part in instrumental, arranging, performance classes, etc. and also provide concert practice, recordings of the orchestra, exams. They have both pedagogical and editing functions, such as Brail note printing, editing the parties for a particular student, learning of the instruments. It is vital to help the participants to reach a concert level in any possible way, including the Internet or modern connection means.
Second, they have to perform the concert master's functions such as toning the instrument, regulation, caring and fixing the instrument, concert and rehearsal activity organization and also material base, such as audio and video recording, special tracks recording, etc. Third, these people should arrange solo or group works for arranging, instrumentation, and conduction classes, to create the notes of the group. Finally, their function is administrative and educative. It means the organization of the concert visiting, performances, museums, theater, colloquiums, lectures, disputes, jubilees, and holiday celebrations.

So the function of the orchestra leader is organizational, administrative, taking into consideration all the needs of the performers.

It is necessary to take into consideration some important specifics of the ensemble-orchestra activity, provided by the RSSAA specifics. It is double responsibility of the participants and the leaders for themselves and the disabled ones, extra terms of the program preparation, longer terms of learning, often from zero level. It is the specifics of the rehearsal sitting and the concerts, rehearsals, entering and leaving the stage. Extra difficulties and special conduction methods, extra sick leaves.

\section{CONCLUSION}

It is necessary to remember that talented blind children from far away villages have the priority of choice of an educational institution on the territory of Russian Federation. Blind children living in big cities are nevertheless less adjusted to existing difficulties. Although they have more opportunities of visiting different cultural and civilization achievements such as theaters, museums, sort competitions or exhibitions, they face great difficulties in moving around big cities: traffic congestion, unequipped underground crossing, lack of traffic lights, human indifference, the inconvenience of public transport usage. Colleges where they study are spread around the city, their parents have to work intensely in order to overcome material difficulties and also try to cure a child, they work away from home and sometimes they can not accompany their children to study.

Perhaps there's a way to break this vicious circle. But are there any real forces able to change anything in this society? Only time will tell. But the fact of the publishing of this article, the interest of many organizations, disabled societies and a long 20-year period of work of the Russian State Specialized Arts`Academy make us hope for the best. 